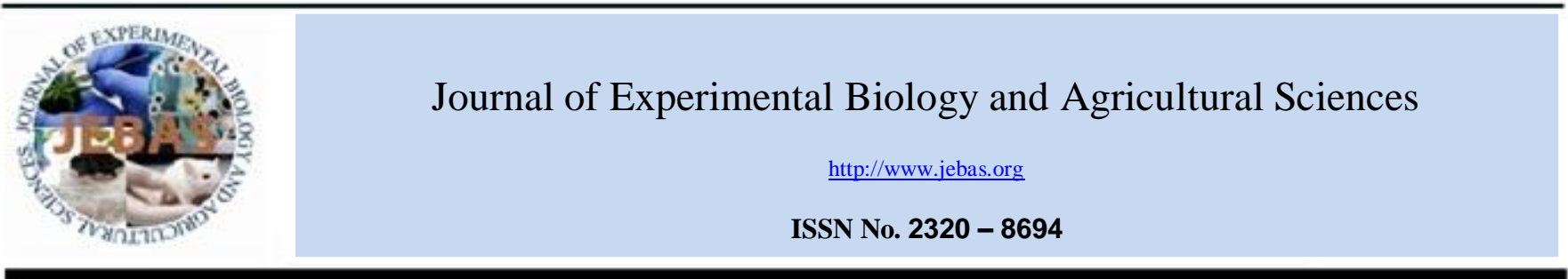

\title{
PRODUCTION SYSTEMS OF SMALL RUMINANTS IN THE ABU-DHABI EMIRATE, UAE
}

\author{
Mohammad J Tabbaa ${ }^{1,2 *}$, Faisal S Barakeh ${ }^{3}$, Maher M Baker ${ }^{4}$ \\ ${ }^{1}$ R\&D, Abu-Dhabi Food Control Authority, P.O Box 52150 Abu-Dhabi, United Arab Emirates. \\ ${ }^{2}$ Department of Animal Production, School of Agriculture, The University of Jordan, Amman, Jordan \\ ${ }^{3}$ Animal Production, Abu-Dhabi Food Control Authority, P.O Box 52150 Abu-Dhabi, United Arab Emirates. \\ ${ }^{4}$ Animal Health, Abu-Dhabi Food Control Authority, P.O Box 52150 Abu-Dhabi, United Arab Emirates.
}

Received - August 02, 2018; Revision - September 21, 2018; Accepted - October 03, 2018

Available Online - October 5, 2018

DOI: http://dx.doi.org/10.18006/2018.6(5).816.827

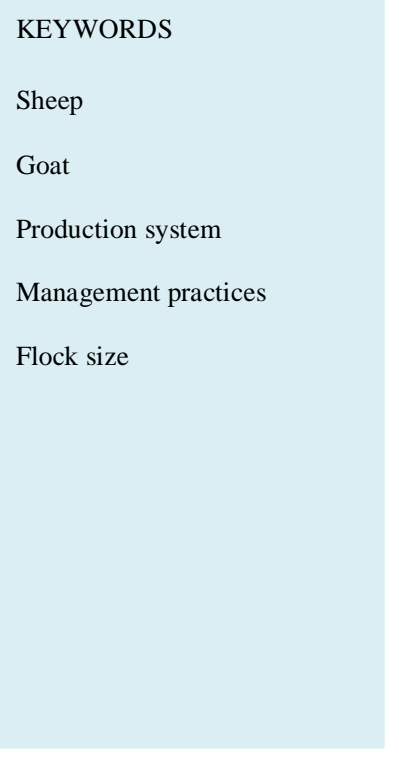

\begin{abstract}
The study was conducted to understand the small ruminants' production systems in the Abu-Dhabi Emirate of the United Arab Emirates and investigate information about utilization, management practices, opportunity and challenges, using a survey. Stratified random samples of 326 farmers from all regions of the Abu-Dhabi Emirate were interviewed. Among these, only $18.7 \%$ of the breeders were females. Emirati farmers were keeping small ruminants mainly for home consumption while less than $5 \%$ were keeping them as a business. The main purpose for keeping small ruminants in the Abu-Dhabi Emirate was meat production as $97 \%$ and $94 \%$ for sheep and goat production, respectively, while milk production was of less concern. Farmers were mostly keeping mixed flocks of 16 sheep and 18 goat breeds, in addition to different crossbreds. The major sheep breeds in the Emirate were Najdi, Awassi (Nuaimi) and Orb whiles the major goat breeds were Local goats, Ardi, Salali, Pakistani and Omani. Differences exist among most studied variables due to different regions, property types, flock size and type. Although, most farmers do not interfere with the daily care of their flocks, the satisfactory proportion of farms were applying many advised management practices. Though, still some good practices are needed to be applied in farmers flocks. The findings of this study create a baseline for understanding the production system of small ruminants in Abu-Dhabi Emirate as the first step in a sustainable production improvement and execution of effective extension program to farmers and labor to improve productivity.
\end{abstract}

* Corresponding author

E-mail: Mohm.tabbaa@ADFCA.AE; MJTabbaa@JU.Edu.Jo(Mohammad J Tabbaa)

Peer review under responsibility of Journal of Experimental Biology and Agricultural Sciences.

Production and Hosting by Horizon Publisher India [HPI] (http://www.horizonpublisherindia.in/).

All rights reserved.
All the article published by Journal of Experimental Biology and Agricultural Sciences is licensed under a Creative Commons Attribution-NonCommercial 4.0 International License Based on a work at www.jebas.org.

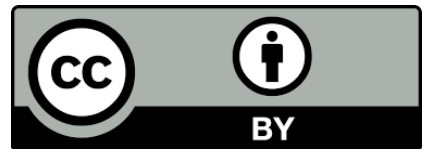




\section{Introduction}

Small ruminants (sheep and goats) have multipurpose roles to sustain the livelihood of farmers and need little investments which could suit both large investors and smallholder farmers. They are characterized with short reproductive cycle, may consume large feeding menu, and adaptable to wide environmental conditions (Degen, 2007; Ahmed et al., 2015; Asefa et al., 2015; Dagnew et al., 2017). They are raised to produce milk, meat, skin and fiber, and provide extra income source (Galal, 2005; Notter, 2012; Asefa et al., 2015; Dagnew et al., 2017). They are the most popular and common livestock in the United Arab Emirate (UAE) with a population exceeds 3.0 million heads in Abu-Dhabi Emirate alone and exceeds 4.3 million heads across the UAE (ADFCA, 2016; FCSA, 2016). Sheep and goat represent the main group of animals in the Emirate, with more than $50 \%$ and $37 \%$ of the total animal heads in the Emirate, respectively (ADFCA, 2016). Though, it is believed that the small ruminant population in the Abu-Dhabi Emirate belongs to several breeds of sheep and goats and their crosses. However, small ruminant production in the UAE is inefficient and not sustainable because of the overutilization of all production inputs (Sherif et al., 2014) which might be due to the fact that farmers in the UAE do not consider it a source of income rather it is a part of their heritage and a source of meat and milk for home consumption, regardless of flock size.

It is of a paramount importance to understand the small ruminants' production systems prevailed in the country which include purpose of keeping, species and breeds raised management and breeding practices applied by farmers, in order for the stakeholders and decision makers setting effective breeding strategies, including the need for financial support, breeding programs and resources plan (Kebede et al., 2012; Asefa et al., 2015; Dagnew et al., 2017). In addition, designing a realistic genetic improvement program for Abu Dhabi Emirate farmers necessitate collecting information about the exact traditional breeding practices (Mbuku et al., 2006; Duguma et al., 2010). Since, no previous studies were available to characterize the production system of small ruminants in the country. Therefore, the objectives were to study the small ruminants' production system and investigate information about utilization of small ruminants, management practices, opportunity and challenges. This study is a significant attempt to understand the small ruminants' production system under United Arab Emirates conditions, which will be beneficial for improvement of small ruminants' productivity and providing the decision makers with realworld information.

\section{Materials and Methods}

\subsection{Selection of the survey area}

A survey was accomplished between December 2015 and September 2016 in the Abu-Dhabi Emirate covering its regions (municipalities) Abu-Dhabi, Al-Ain and Al-Dhafra. The AbuDhabi Emirate is located between $22^{\circ} 40^{\prime \prime}$ and $25^{\circ} \mathrm{N}$ and $51^{\circ}$ and $56^{\circ} \mathrm{E}$ and characterized with hot desert climate, low rainfall, and mostly clear skies all-year-round. Average maximum annual temperature exceeds $39^{\circ} \mathrm{C}$ with high humidity during the period from June to September, while cooler temperatures $\left(19^{\circ} \mathrm{C}\right)$ are experienced from November to March.

\subsection{Sampling procedure}

Researchers interviewed 326 breeders randomly selected according to a stratified random sampling procedure from all regions of the Emirate depending on small ruminant population in each sub-region (ADFCA, 2013). The sample size was determined based on having 5 breeders for each one percent of the small ruminant population, with a minimum of 3 breeders in a subregion. Breeders under investigation own a total of 406 and 319 flocks of different sheep and goat breeds, with a total of 80401 and 49911 heads, respectively.

\subsection{Interview procedure}

A questionnaire was prepared to collect information related to small ruminant breeding practices in Abu-Dhabi Emirate. Breeders were asked about their ruminant flock size and structures, breeds owned, and uses of the animals (FAO, 2012). The questionnaire also included general information about the owner and the farm. Infrequent breeds that were found in only one or two farms were grouped together in one group named "Others". In Abu-Dhabi Emirate, small ruminants are not allowed to graze outside the farmers' properties which are of 3 types: registered animal farms, random animal farms and mixed farms (Tabbaa \& Hassanin, 2017). Flocks were of three types either pure sheep, pure goat or mixed of both species and were classified as small if the number of adult animals is between 30 to 150 heads, medium if the number is between 151 to 350 heads and large if the number is exceeding 350 heads.

\subsection{Statistical analysis}

Preliminary stepwise analysis of variance was performed for all possible factors including gender of farmer, region, property type, flock size and type with their interactions to study their influence on the continuous variable in the survey using GLM procedure (SAS, 2009). Though, interactions did not meet the condition of significance $(\mathrm{P}=0.25)$, therefore, they were removed from the final analysis model. Means for significant effects were compared at $\mathrm{P}<0.05$ using independent t-test. Qualitative survey data were statistically analyzed using the Chi-square test using PROC FREQ procedure (SAS, 2009). 


\section{Results and Discussion}

\subsection{Socioeconomic role}

The results of this study revealed that $18.7 \%$ of the interviewed breeders were females with no significant differences among the different regions of Abu-Dhabi Emirate (Table 1). Similar ratios of female farmers across regions were found in other countries (Kebede et al., 2012; Asefa et al., 2017; Onzima et al., 2018). However, gender of farmer was significantly $(\mathrm{P}<0.05)$ different among different types of property; female farmers represent $23.4 \%$ of the municipality registered animal farms, and $22.7 \%$ of the mixed farms and only $10.3 \%$ of the random animal farms. The first two types of properties were created by each municipality as adjacent groups of farms and allocated to different local farmers and provided veterinary and logistic services such as municipality water, and subsidized feed. Though, some farmers created their own farms in random places which could be in groups or singles and unable to be registered at the municipalities which could justify the lower percentage of female farmers in the random animal farms. Registered and random animal farms were allowed to raise animals without growing trees or producing crops. On the other hand, mixed farms were allowed to grow trees, and produce crops and vegetables besides keeping animals. Due to these differences, different property types may correspond to different production systems. The distribution of property types was highly significantly $(\mathrm{P}<0.001)$ different among the different regions of

Table 1 Distribution of surveyed farms according to regions in Abu-Dhabi Emirate.

\begin{tabular}{|c|c|c|c|c|c|}
\hline \multicolumn{5}{|c|}{ Overall } & \multirow[t]{2}{*}{ P-value } \\
\hline $\mathrm{N}$ & 326 & 81 & 183 & 62 & \\
\hline $\begin{array}{l}\text { Gender of } \\
\text { farmers } \%\end{array}$ & 18.7 & 16.0 & 19.7 & 19.3 & 0.78 \\
\hline \multicolumn{5}{|c|}{ Properety type } & $<0.0001$ \\
\hline $\begin{array}{c}\text { Registered farm } \\
\%\end{array}$ & 14.4 & 34.6 & 9.84 & 1.6 & \\
\hline Mixed farming $\%$ & 52.8 & 9.9 & 66.7 & 67.7 & \\
\hline Random farm \% & 32.8 & 55.6 & 23.5 & 30.7 & \\
\hline \multicolumn{5}{|c|}{ Flock size $^{1}$} & 0.0089 \\
\hline Small \% & 31.9 & 44.4 & 29.0 & 24.2 & \\
\hline Medium \% & 40.2 & 40.7 & 37.7 & 46.8 & \\
\hline Large $\%$ & 27.9 & 14.8 & 33.3 & 29.0 & \\
\hline \multicolumn{5}{|c|}{ Flock type } & 0.009 \\
\hline Pure goat $\%$ & 10.4 & 16.0 & 10.9 & 1.6 & \\
\hline Pure sheep $\%$ & 17.8 & 23.5 & 17.5 & 11.3 & \\
\hline Mixed flock \% & 71.8 & 60.5 & 71.6 & 87.1 & \\
\hline
\end{tabular}

Flock size: small $=<150$, medium $151-350$ and large $>350$ heads. the Emirate. Most of the Abu-Dhabi region farms were random farms and the least was the mixed farms. Al-Ain, which historically known for its relative land fertility and availability of irrigation water, and in consequence presence of old farms, its most available type of property was mixed farms and least were the registered farms and similarly was Al-Dhafra region. Distribution of production or herding systems of small ruminants was also different among different regions of Ethiopia as reported by Asefa et al. (2015) and Asefa et al. (2017).

\subsection{Goal and purpose of rearing}

Farmers of the UAE were keeping small ruminants mainly as a tradition inherited from their ancestors with no specific goal of keeping them for many farmers. In addition, the culture of UAE people is to trust that they should see the animal alive before being slaughtered in front of them, and they prefer the taste of certain breeds of sheep and goat which could be different for different people (Figure 1 and 2). Regardless of flock size and type or gender of farmer, $47.6 \%$ of farmers usually kept small ruminants for home consumption only and another $47.6 \%$ of farmers sell the surplus mainly to relatives and extended family members while only $4.8 \%$ consider keeping small ruminants as a business. The goal of keeping small ruminants in other parts of the world was varied. In other countries, generating income was among the most important goal for both sheep and goat followed by home consumption (Nandolo et al., 2016; Abraham et al., 2017; Asefa et al., 2017; Dagnew et al., 2017). Though, home consumption was the major goal of keeping small ruminants as reported by other researchers (Kebede et al., 2012; Asefa et al., 2015). Regions and property types' differences were significantly influenced goal of farmers ( $\mathrm{P}<0.01$, Table 2$)$. Only $2.5 \%$ of the Abu-Dhabi region farmers considered keeping small ruminants for business reasons and more than $67 \%$ of farmers keep small ruminants only for home consumption while $6.7 \%$ of the $\mathrm{Al}$ Dhafra region farmers considered keeping small ruminants for business reasons. Similarly, Nandolo et al. (2016) reported goals of keeping small ruminants to be different among farmers of different regions and production systems in Malawi. In Abu Dhabi Emirate, only around 2\% of farmers of the registered and random animal farms considered keeping small ruminants for business reasons while around $60 \%$ of farmers of other property types kept small ruminants for home consumption only. Farmers of mixed farms were more confident to do business with small ruminants as both business and selling surplus options with $7.1 \%$ and $56.6 \%$, respectively while lower proportion of farmers kept their small ruminants for home consumption only.

The purpose for keeping small ruminants was reported to be affected by countries, regions, breeds, production systems and herd size (Kebede et al., 2012; Rose, 2014; Santos et al., 2015; 

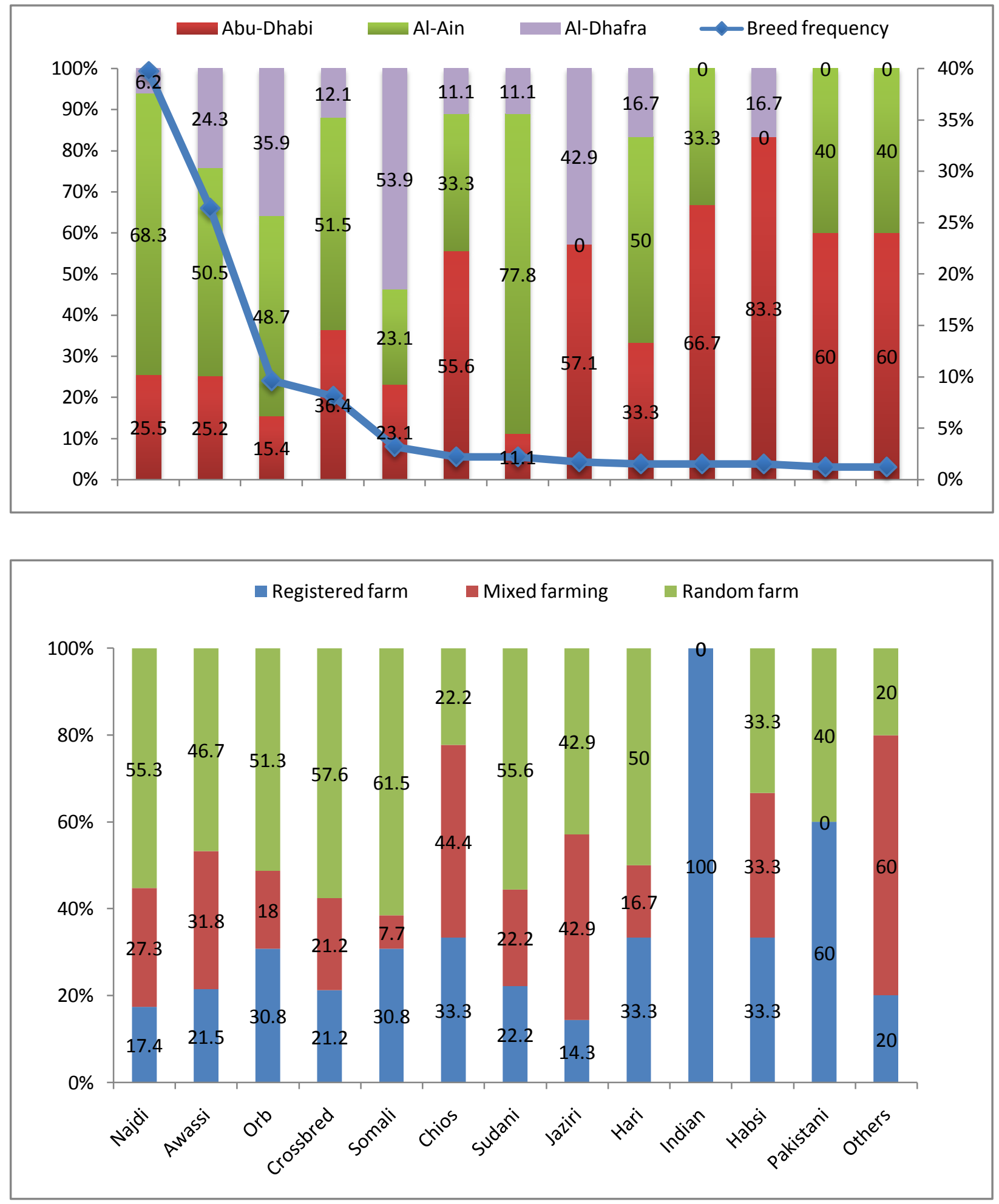

Figure 1 Distribution of flocks of sheep breeds according to farm region and property type (Others (American, Afghani, South African, Omani and Muflon); Region and property type distributions were significantly different among breeds $(\mathrm{P}<0.0001)$ and $(\mathrm{P}=0.012)$, respectively) 

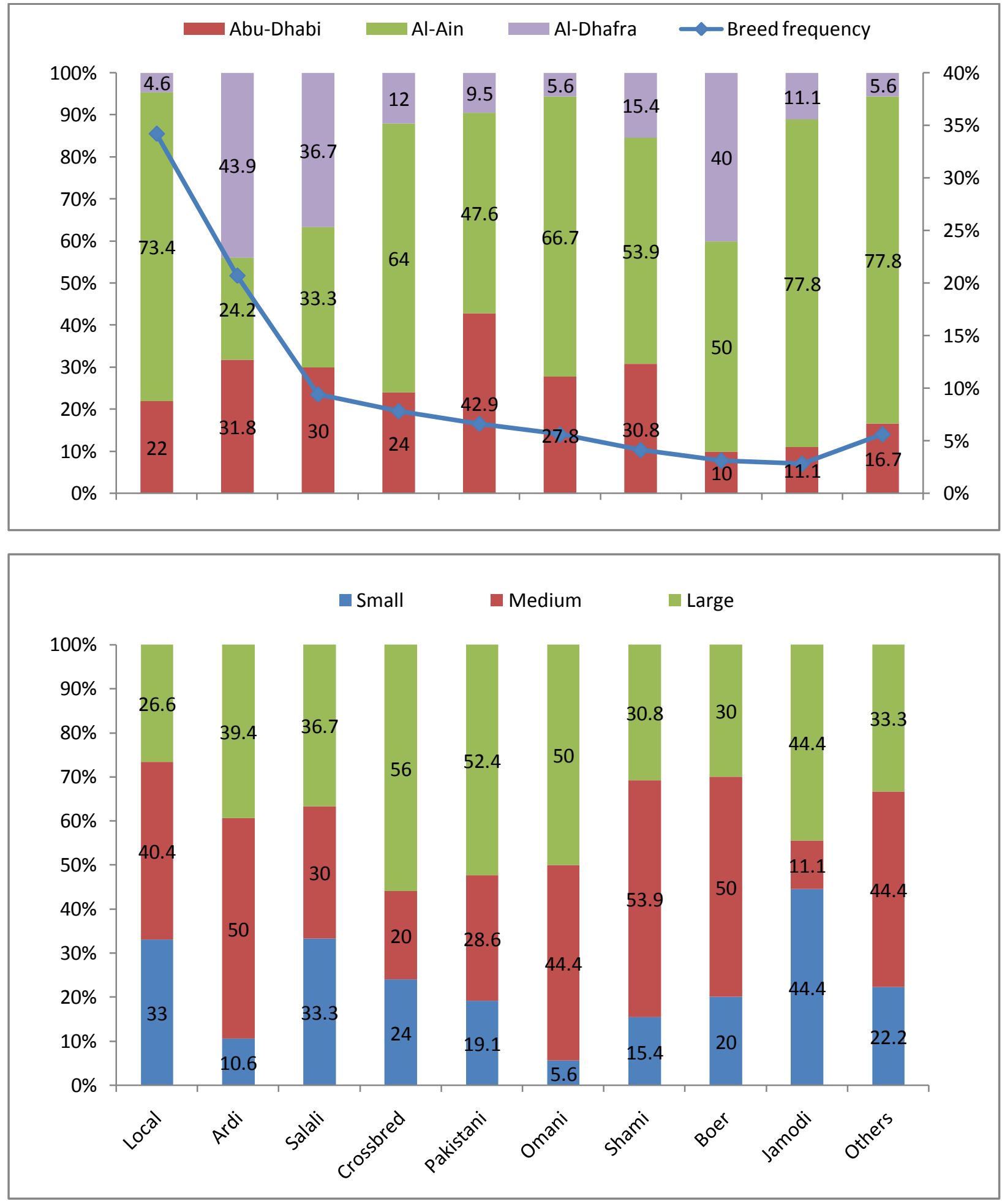

Figure 2 Distribution of flocks of goat breeds according to farm region and flock size (Others (African, Haw, Hawarez, Jabali, Maltese, Saanen, Zafari, Saedi, Rahbi and Somali); Flock size: small $=<150$, medium $151-350$ and large $>350$ heads; Region and flock size distributions were significantly different among breeds $(\mathrm{P}<0.0001)$ and $(\mathrm{P}=0.024)$, respectively $)$

Journal of Experimental Biology and Agricultural Sciences http://www.jebas.org 
Table 2 Factors affecting the goal of keeping small ruminant by farmers of Abu-Dhabi Emirate

\begin{tabular}{|lcc|cc|}
\hline Variable & Bussiness $\%$ & $\begin{array}{c}\text { Home } \\
\text { consumption\% }\end{array}$ & $\begin{array}{c}\text { Selling } \\
\text { surplus } \\
\%\end{array}$ & $\begin{array}{c}\text { P- } \\
\text { value }\end{array}$ \\
\hline Overall $\%$ & 4.8 & 47.6 & 47.6 & \\
\hline \multicolumn{5}{|c|}{ Region } \\
\hline Abu-Dhabi & 2.5 & 67.1 & 30.4 & \\
\hline Al-Ain & 5.1 & 39.2 & 55.7 & 0.0015 \\
\hline Al-Dhafra & 6.7 & 46.7 & 46.7 & \\
\hline & & Properety type & & \\
\hline $\begin{array}{l}\text { Registered } \\
\text { farm }\end{array}$ & 2.1 & 57.5 & 40.4 & \\
\hline $\begin{array}{l}\text { Mixed } \\
\text { farming }\end{array}$ & 7.1 & 36.3 & 56.6 & \\
\hline $\begin{array}{l}\text { Random } \\
\text { farm }\end{array}$ & 2.0 & 62.0 & 36.0 \\
\hline
\end{tabular}

Dagnew et al., 2017). The main purpose for keeping small ruminants in the Abu-Dhabi Emirate was meat production as 97\% and $94 \%$ for sheep and goat production, respectively, with no significant differences found due to all studied factors. Similarly, sheep and goat farmers in many parts of the world such as Malawi, Ethiopia, New Zealand, Ireland and Portugal were keeping small ruminants mainly for meat production (Tibério \& Diniz, 2014; Santos et al., 2015; Nandolo et al., 2016; Dagnew et al., 2017). In Abu Dhabi Emirate, milk production from both sheep and goat was not of major concern, as only $10 \%$ and $21 \%$, respectively of farmers for both species, who milk their female animals to make yoghurt or some types of cheese, mainly used for home consumption. Though, milk was more important from goat than that from sheep, which is similar to that reported by Tibério \& Diniz (2014) for the small ruminants in Portugal. It is the main purpose for keeping goat in many parts of the world including Jordan (Tabbaa \& Al-Atiyat, 2009), some district of Ethiopia (Asefa et al., 2015). However, sheep in Jordan was also kept for milk production (Abu-Zanat et al., 2005). Though, significant ( $\mathrm{P}<$ 0.05 ) differences were found among regions as the Al-Dhafra had the highest proportion of farmers interested in milking their sheep and goats (21\% and $25 \%$, respectively), secondly were farmers in the Abu-Dhabi region ( $8 \%$ and $23 \%$, respectively), and the least were farmers in the Al-Ain region ( $8 \%$ and $9 \%$, respectively). Lopes et al. (2013) suggested that the importance of milk production was different among regions due to economic, ecological and cultural factors. Fewer farmers were interested in fiber production (2-3\%). Although, farmers shear their sheep and goats during April and May, they throw wool and hair in the waste. Similarly, other purposes such as skin and manure were less important as reasons for keeping small ruminants (Asefa et al., 2015).

\subsection{Flock size and structure}

Flock sizes of small ruminants in the Abu-Dhabi Emirate in this survey were ranging from small flocks $(32 \%)$ of 30 to 150 total adult heads and with an average of $148 \pm 24$, medium (40\%) with total adults between 151 and 350 heads and with an average of $325 \pm 24$, and $28 \%$ large with a total adults more than 350 heads and with an average of $797 \pm 28$. Similar average flock size was reported for small ruminants in Jordan (Abu-Zanat et al., 2005), while much smaller average flock size was reported for sheep and goat in Ethiopia (Asefa et al., 2015; Ahmed et al., 2015; Asefa et al., 2017). The overall average flock size was $289 \pm 13$ adult heads and total was $400 \pm 18$ heads of all ages. Small ruminant flock size distribution was significantly different among regions $(\mathrm{P}<0.01)$, in Abu-Dhabi region, flock sizes tended to be small to medium while in Al-Dhafra region they were mostly medium and those in Al-Ain were almost evenly distributed among all different sizes with slightly higher proportion of medium size flocks (Table 1). In Ethiopia, regional differences in flock size were found in sheep flocks but not in goat flocks (Asefa et al., 2015; Asefa et al., 2017).

More than $70 \%$ of the flocks were mixed of both sheep and goats while $17.8 \%$ were pure sheep flocks and $10.4 \%$ were pure goat flocks (Table 1). However, highly significant $(\mathrm{P}<0.01)$ differences were found among regions, as more than $87 \%$ of AlDhafra flocks were of mixed type and less than $2 \%$ were pure goats, in Abu-Dhabi region 16\% were pure goat flocks and only $60.5 \%$ of the flock were mixed, and flock type distribution of AlAin were in between the distribution of the two regions. In both the overall and mixed flocks, around $60 \%$ of the flock was sheep and $40 \%$ was goats which could reflect the preference of sheep meat by most local people of Abu-Dhabi Emirate (Table 3). Though, $40 \%$ of goats represent high proportion with relative to that reported in the Middle and Northern parts of Jordan 5\% and $14 \%$, respectively (Abu-Zanat \& Tabbaa, 2004; Abu-Zanat et al., 2005). Many local UAE people prefer the goat meat and demand is increasing (Ahmed et al., 2015). As expected, both sheep and goat total numbers increased by increasing flock size and their numbers were higher in the pure flocks than that in mixed flock. Though, goat total number was highest in the random farms and lowest in the registered farms (Table 3). As flock size increase significantly $(\mathrm{P}<0.001)$ proportion of mixed type increase from $53.9 \%$ for small flocks, to $74.0 \%$ for medium flocks and to $89.0 \%$ for large flocks. On the contrary, Dagnew et al. (2017) reported that mixing decrease by flock size increase in Ethiopia.

As Table 3 revealed, more than $66 \%$ and $6 \%$, respectively, of the flocks were adult females (ewes and does) and males (rams and bucks) as adult males are used for serving the adult females in the flock. Registered farms had the highest percentage of adult females followed by random farms while random farms had the highest percentage of adult males followed by registered farms. 
Table 3 Factors affecting the structure of farmers of small ruminants' flocks in Abu-Dhabi Emirate.

\begin{tabular}{|c|c|c|c|c|c|c|c|}
\hline Variable & Sheep total & Goat total & Adult females \% & Adult males \% & Youngs $^{1} \%$ & $\begin{array}{c}\text { Replacement }{ }^{2} \\
\text { females } \%\end{array}$ & $\begin{array}{c}\text { Replacement }^{2} \\
\text { males } \%\end{array}$ \\
\hline Overall & $278.2 \pm 13.9$ & $190.5 \pm 10.6$ & $66.4 \pm 0.7$ & $6.2 \pm 0.4$ & $17.1 \pm 0.4$ & $8.7 \pm 0.5$ & $1.5 \pm 0.1$ \\
\hline Region & 0.092 & 0.41 & 0.19 & 0.0002 & 0.35 & 0.050 & 0.0007 \\
\hline Abu-Dhabi & $350.0 \pm 22.6$ & $203.8 \pm 21.6$ & $67.6 \pm 1.6$ & $4.6 \pm 0.9^{b}$ & $15.9 \pm 1.0$ & $9.8 \pm 1.1^{\mathrm{a}}$ & $2.1 \pm 0.3^{\mathrm{a}}$ \\
\hline Al-Ain & $316.4 \pm 19.4$ & $213.4 \pm 18.3$ & $68.9 \pm 1.4$ & $6.1 \pm 0.8^{b}$ & $16.6 \pm 0.9$ & $7.6 \pm 0.9^{\mathrm{ab}}$ & $0.8 \pm 0.3^{b}$ \\
\hline Al-Dhafra & $366.5 \pm 27.0$ & $183.8 \pm 26.1$ & $65.6 \pm 2.1$ & $9.5 \pm 1.1^{\mathrm{a}}$ & $17.9 \pm 1.2$ & $6.1 \pm 1.3^{\mathrm{b}}$ & $0.9 \pm 0.4 \mathrm{~b}^{\mathrm{b}}$ \\
\hline Properety type & 0.072 & 0.020 & 0.020 & 0.013 & 0.80 & $<0.0001$ & 0.13 \\
\hline Registered farm & $379.3 \pm 29.3$ & $158.4 \pm 27.2^{\mathrm{b}}$ & $70.8 \pm 2.2^{\mathrm{a}}$ & $6.1 \pm 1.2^{\mathrm{ab}}$ & $16.3 \pm 1.3$ & $5.7 \pm 1.4^{\mathrm{b}}$ & $1.1 \pm 0.4$ \\
\hline Mixed farming & $343.3 \pm 17.7$ & $207.0 \pm 18.7^{\mathrm{ab}}$ & $64.4 \pm 1.4^{\mathrm{b}}$ & $5.8 \pm 0.7^{\mathrm{b}}$ & $17.2 \pm 0.8$ & $11.0 \pm 0.9^{\mathrm{a}}$ & $1.6 \pm 0.3$ \\
\hline Random farm & $310.2 \pm 21.9$ & $235.7 \pm 20.2^{\mathrm{a}}$ & $67.0 \pm 1.6^{\mathrm{ab}}$ & $8.3 \pm 0.8^{\mathrm{a}}$ & $16.9 \pm 0.9$ & $6.9 \pm 1.0^{\mathrm{b}}$ & $1.0 \pm 0.3$ \\
\hline Flock size $^{3}$ & $<0.0001$ & $<0.0001$ & 0.21 & 0.88 & 0.14 & 0.38 & 1.00 \\
\hline Small & $152.3 \pm 21.7^{\mathrm{c}}$ & $82.3 \pm 20.6^{\mathrm{c}}$ & $65.5 \pm 1.5$ & $6.5 \pm 0.8$ & $18.0 \pm 0.9$ & $8.8 \pm 1.0$ & $1.2 \pm 0.3$ \\
\hline Medium & $288.8 \pm 20.0^{\mathrm{b}}$ & $167.1 \pm 19.9^{b}$ & $68.1 \pm 1.5$ & $6.7 \pm 0.8$ & $16.7 \pm 0.9$ & $7.3 \pm 1.0$ & $1.2 \pm 0.3$ \\
\hline Large & $591.8 \pm 22.7^{\mathrm{a}}$ & $351.7 \pm 22.3^{\mathrm{a}}$ & $68.5 \pm 1.8$ & $7.0 \pm 1.0$ & $15.8 \pm 1.1$ & $7.5 \pm 1.1$ & $1.2 \pm 0.3$ \\
\hline Flock type & $<0.0001$ & 0.0037 & 0.15 & 0.90 & 0.56 & 0.0034 & 0.48 \\
\hline Pure goat & & $239.9 \pm 27.4^{\mathrm{a}}$ & $69.0 \pm 2.4$ & $7.0 \pm 1.3$ & $16.2 \pm 1.4$ & $6.8 \pm 1.5^{\mathrm{b}}$ & $0.9 \pm 0.4$ \\
\hline Pure sheep & $413.1 \pm 25.1^{\mathrm{a}}$ & & $64.9 \pm 1.9$ & $6.7 \pm 1.0$ & $16.6 \pm 1.1$ & $10.4 \pm 1.2^{\mathrm{a}}$ & $1.4 \pm 0.3$ \\
\hline Mixed flock & $275.4 \pm 14.5^{\mathrm{b}}$ & $160.8 \pm 12.8^{b}$ & $68.2 \pm 1.1$ & $6.5 \pm 0.6$ & $17.5 \pm 0.6$ & $6.4 \pm 0.7^{b}$ & $1.4 \pm 0.2$ \\
\hline
\end{tabular}

The least percentage of adult males was in Abu-Dhabi region while the highest percentage of adult males was in Al-Dhafra region. Region effect was also found to influence ratios of adult males and females of sheep but not adult goat females in Ethiopia (Asefa et al., 2015; Asefa et al., 2017). Young lambs and kids of less than 6 months of age represent $17.1 \%$ with no significant differences among all studied factors. Proportions of replacements were $1.5 \%$ and $8.7 \%$ for male and female, respectively. Males were always less than females since the producing animals are always the female and fewer males are needed for serving the females in the flock. Ratios reported by Ahmed et al. (2015) were much higher than the values found in this study. However, replacements proportions were significantly different in different regions and they were higher in Abu-Dhabi region than that in each of Al-Ain and Al-Dhafra. The proportion of female replacements was also significantly $(\mathrm{P}<0.01)$ influenced by property and flock types, mixed farming and pure sheep flocks had the highest proportions, which could reflect higher stability in these flocks and the intention to increase their sizes. Similarly, Abu-Zanat \& Tabbaa (2004) found comparable proportions of different ages and sexes for small ruminants' flocks in Jordan.

\subsection{Small ruminants breeds}

Farmers of Abu-Dhabi Emirate were found to raise 16 and 18 different pure breeds of sheep and goats, respectively in addition to different crossbreds (Figure 1,2). The most frequent breeds of sheep flocks in the Emirate were Najdi (39.7\%), Awassi (Nuaimi, $26.4 \%$ ), and Orb (9.6\%) then followed by different crossbreds $(8.1 \%)$ while other breeds were represented by less than $5 \%$ of the flocks (Figure 1). Orb is the local Emirati sheep, and it is medium in size has a thin tail that is a little thick in the base, dark brown to black in color and adapted to the hot environment of UAE (Alhadrami et al., 1997; Al-Shorepy, 2004). In 2004, Orb breed was used to represent $30-35 \%$ of the sheep population in the UAE (Al-Shorepy, 2004). Orb sheep population distribution decreased significantly probably due to that Najdi and Awassi are very important in the livestock shows in the Arabian Gulf area. These shows are called in the local language "Muzaianah" where animals are exhibited and judged based on experience of the judgment team but not on precise measurements. Though, breed unique morphological characteristics are considered and winners are paid very high prices for the highly ranked individual animals. 
The distribution of these breeds was significantly different among regions ( $\mathrm{P}<0.001)$. Asefa et al. (2017) reported differences in sheep breed distributions among different regions of Ethiopia. AlAin region had the highest proportions of these major breeds while the other two regions had lower proportions with different ratios. Although, Abu-Dhabi region has almost all different breeds, the minor breeds with less than 5\% frequency of their flocks were not found in all regions. Property type also significantly $(\mathrm{P}<0.05)$ influenced the distribution of sheep breeds, where random animal farms had the highest proportions of most breeds while the registered animal farms had almost all different breeds.

Figure 2 show the distribution of goat breeds flocks as the most frequent breeds were Local Emirati or simply Local goats (34.2\%), Ardi (20.7\%), Salali (9.4\%), Pakistani (6.6\%) and Omani (5.6\%), while the different crossbreds represented by $7.8 \%$ and other breeds represented by less than $5 \%$ of the flocks. Emirati goat breed is considered highly adapted to the harsh environmental conditions of UAE; both sexes have horns and black colour with a brown or white belly and with brown or white smears on its face and legs, with light weight of about $26 \mathrm{~kg}$ (AlShorepy et al., 2002). The region has the most important and significant $(\mathrm{P}<0.001)$ effect on the flocks of goat breeds distribution, with Al-Ain having the highest proportion of the Local goats, Pakistani and Omani breeds beside several minor breeds, while Ardi and Salali breeds were more frequent in AlDhafra region. Similarly, Al-Atiyat et al. (2015) reported that goat breeds diversity was due to morphological and regional differences. The distribution of flocks of goat breeds was also significantly $(\mathrm{P}<0.05)$ influenced by flock size with medium flocks had the highest proportion of Local goats and Ardi breeds beside several minor breeds while large flocks had the highest proportion of Salali, Pakistani and Omani breeds.

\subsection{Keeping other animals}

Besides keeping small ruminants, $62.2 \%$ of farmers of Abu-Dhabi Emirate were keeping other animals which included camels (54.8\%), poultry (43.7\%) and cattle (38.2\%), in addition to many other species of different animals (Table 4). Farmers keep different livestock species and breeds to improve complementary in their flocks and decrease climatic risks (Al-Khaza'leh et al., 2016). Male farmers were significantly $(P<0.05)$ keeping other animals than females. Also, farmers of mixed flocks were significantly $(\mathrm{P}<0.01)$ keeping other animals more than those keeping pure flocks of either sheep or goats. Region significantly ( $\mathrm{P}<0.01)$ influenced percentage of farmers keeping camel, poultry and cattle. Similarly, region was found to affect the presence and percentage of different livestock species kept by farmers in other countries (Gatew et al., 2017; Onzima et al.,
2018). Farmers of Al-Dhafra region which is mostly desert extended to Saudi Arabia were keeping camels almost twice the farmers of Abu-Dhabi region and almost 50\% more than Al-Ain farmers. The people of Al-Dhafra region were used camels traditionally for transportation more than other regions, though nowadays they are used only for Muzaianah and race. However, farmers of Abu-Dhabi region which is closer to the sea and its port were keeping poultry almost twice the farmers of Al-Ain region and more than $25 \%$ more than Al-Dhafra farmers. Poultry kept by farmers in the Emirate include mainly village chicken in addition to, turkeys, ducks, geese, pigeons, quails and partridges. Traditionally, keeping backyard poultry was an easy job, beside that, farmers of Abu-Dhabi region were used to sell poultry easily to the visitors coming through the port which was the main gate to the world. On the other hand, farmers of Al-Ain region, which has traditionally more fertile land, were keeping cattle more than

Table 4 Percentage of farmers keeping other animals in their farms beside the small ruminants and factors affecting them

\begin{tabular}{|c|c|c|c|c|c|}
\hline Variable & $\begin{array}{l}\text { Keeping other } \\
\text { animals } \%\end{array}$ & Camel \% & Poultry $\%$ & $\begin{array}{c}\text { Cattle } \\
\%\end{array}$ & $\begin{array}{c}\text { Other } \\
\text { species \% }\end{array}$ \\
\hline Overall & 62.2 & 54.8 & 43.7 & 38.2 & 27.6 \\
\hline $\begin{array}{l}\text { Gender of } \\
\text { farmers }\end{array}$ & 0.015 & 0.74 & 0.74 & 0.47 & 0.83 \\
\hline Male & 65.3 & 55.2 & 44.2 & 37.2 & 27.9 \\
\hline Female & 48.3 & 51.9 & 40.7 & 44.4 & 25.9 \\
\hline Region & 0.13 & 0.0007 & 0.0014 & 0.0003 & 0.15 \\
\hline $\begin{array}{l}\text { Abu- } \\
\text { Dhabi }\end{array}$ & 67.9 & 40.0 & 61.8 & 23.6 & 32.7 \\
\hline Al-Ain & 57.4 & 53.3 & 32.4 & 51.4 & 21.9 \\
\hline Al-Dhafra & 68.9 & 79.5 & 48.7 & 23.1 & 35.9 \\
\hline $\begin{array}{l}\text { Properety } \\
\text { type }\end{array}$ & 0.067 & $<0.0001$ & 0.0002 & 0.43 & 0.0013 \\
\hline $\begin{array}{l}\text { Registered } \\
\text { farm }\end{array}$ & 76.6 & 72.2 & 63.9 & 36.1 & 16.7 \\
\hline $\begin{array}{c}\text { Mixed } \\
\text { farming }\end{array}$ & 61.4 & 66.0 & 30.1 & 35.0 & 21.4 \\
\hline $\begin{array}{l}\text { Random } \\
\text { farm }\end{array}$ & 57.0 & 25.0 & 55.0 & 45.0 & 45.0 \\
\hline $\begin{array}{c}\text { Flock } \\
\text { size }^{1}\end{array}$ & 0.087 & 0.73 & 0.17 & 0.0071 & 0.68 \\
\hline Small & 61.5 & 58.1 & 33.9 & 29.0 & 30.7 \\
\hline Medium & 56.5 & 51.4 & 47.3 & 32.4 & 28.4 \\
\hline Large & 71.1 & 55.6 & 49.2 & 54.0 & 23.8 \\
\hline Flock type & 0.0015 & 0.79 & 0.003 & 0.0093 & 0.11 \\
\hline Pure goat & 47.1 & 62.5 & 18.8 & 25.0 & 25.0 \\
\hline $\begin{array}{l}\text { Pure } \\
\text { sheep }\end{array}$ & 46.6 & 51.9 & 22.2 & 14.8 & 44.4 \\
\hline $\begin{array}{l}\text { Mixed } \\
\text { flocks }\end{array}$ & 68.2 & 54.5 & 50.0 & 43.6 & 25.0 \\
\hline
\end{tabular}

Flock size: small $=<150$, medium $151-350$ and large $>350$ heads. 
twice each of the other two regions (Table 4). Breed of Local cattle was used to be used for cultivation of farms beside that AlAin region has 14 large specialized dairy farms and processing plants where stallholder farmers send their milk to be processed which could reasons behind keeping more cattle in Al-Ain than other regions.

Property type significantly $(\mathrm{P}<0.001)$ influenced the proportion of farmers keeping camels, poultry and other animal species. Proportion of registered farm then mixed farm farmers were keeping camels much more than random farm farmer, which could be related to the services provided by the municipalities such as veterinary services, water and feed subsidy. Lower proportion of mixed farmers were keeping poultry probably due to that keeping free poultry in vegetable farms could be harmful. On the other hand, higher proportion of farmers of random farms was keeping other species of animals more than twice the farmers of other property types. Other species of animals include food animals such as rabbits, deer, ostrich, and peacock beside nonfood animals, such as dogs, horses and apes. These animals were not subsidized; therefore, they were mostly kept as a hobby, although, some farmers keep them for commercial purposes. In general, as flock size increased proportion of farmers keeping cattle were significantly $(\mathrm{P}<0.01)$ increased. Flock type significantly $(\mathrm{P}<0.01)$ influenced proportion of farmers keeping poultry and cattle. Higher proportion of farmers who had mixed flocks was keeping poultry and cattle than those had pure flocks of either sheep or goats.

\subsection{Housing and management practices}

Small ruminants in Abu-Dhabi Emirate were raised in partly shaded open houses that were mostly sufficiently shaded (75\%). Similar results were found in all UAE where farmers housing their animals in separate shades for each group of animals (Sherif et al., 2014). Though, shaded sufficiency was significantly $(\mathrm{P}<0.05)$ different according to flock size, as large flocks had better shades $(87 \%)$ than both medium $(71 \%)$ and small flocks $(69 \%)$. The insufficient shading would increase the heat load on the small ruminants especially during the hot summer season when temperature sometimes could rise above $50^{\circ} \mathrm{C}$ which could lead to increase mortality and reduce productivity if high stock density also prevailed. However, in colder places did not require such shade except for few hours in some hot days. Therefore, only fences and trees are needed to keep or separate different groups of animals (Asefa et al., 2015).

Newly introduced animals should be isolated or quarantined before being mixed with other animals in the flock. Quarantine is a very important practice to reduce introduction of new diseases to the existed flocks (VSCEAH, 2015). In this study, only 59.3\% of Abu-Dhabi Emirate farmers were practicing quarantine before introducing new animals to their small ruminant flocks (Table 5). However, only $40.2 \%$ of the sheep farms in the USA quarantined their newly arrived animals in 2010 as reported by the U.S. Department of Agriculture's National Animal Health Monitoring System (NAHMS) (VSCEAH, 2015). However, significantly ( $\mathrm{P}$ $0.05)$ more male farmers were practicing quarantine than female farmers. The regional differences were more significantly $(\mathrm{P}<$ 0.001) distinct; as Al-Dhafra farmers were practicing animal quarantine more than either of al-Ain and Abu-Dhabi region farmers. Also, significantly $(\mathrm{P}<0.01)$ less registered animal farm farmers were practicing quarantine to their newly introduced animal than mixed farm and random farm farmers. Also, frequency of farmers practicing quarantine significantly $(\mathrm{P}<0.01)$ increased by increasing the flock size, since they had good awareness about the importance of quarantine in saving their flocks from introduction of new diseases.

Since small ruminants were not allowed to graze outside the farmers' properties, farmers were feeding their animals alfalfa and grasses hay. Extra needed amount may be bought from the free market or the government with regular prices. Farmers were feeding these roughages as $1.5 \mathrm{~kg}$ daily per animal divided into two to three portions for both sheep and goats regardless of their physiological status, productivity or nutritional requirements. In addition, some farmers prefer to feed their small ruminants some ready mixed concentrate available from the feed companies in the UAE market, as the government used to provide $40 \%$ concentrate and $60 \%$ roughages with the subsidized prices. Though, more than $70 \%$ of the farmers practice fattening of the young lambs and kids to obtain higher body weights, with significant $(\mathrm{P}<0.001)$ differences found among farmers of the different regions and property types (Table 5). On the contrary only less than $20 \%$ of goat farmers in Ethiopia practice fattening (Asefa et al., 2015). In Al-Dhafra where farmers considered keeping small ruminants for commercial reasons, had the highest proportion of farmers practicing fattening followed with farmers of Al-Ain then AbuDhabi regions. Farmers of mixed farms also were the most concerned with fattening followed by random farm farmers.

More than $70 \%$ of the farmers were interested in breed purity even though they were keeping several breeds of small ruminants; with only significant $(\mathrm{P}<0.01)$ differences were due to flock type, as farmers of pure sheep flock were the most interested and the least interested were farmers of pure goat flock (Table 5). Muzaianah of Najdi and Awassi sheep might be responsible as they judged based on their unique morphological characteristics more than other species or breeds. However, recently Boer, Ardi and Shami goat breeds were also exhibited in the livestock shows in the Abu-Dhabi Emirate to be ranked. In this study, 29.1\% of the farmers were mixing breeds together with no specific purpose most of the time, with no significant $(\mathrm{P}>0.1)$ differences due to 
all studied factors (Table 5). Since sheep and goat do not mate together, many farmers also put them together if they do not have enough separate areas. Similarly, farmers in Kenya and Ethiopia practice pure-breeding for some specific breeds while farmers of other breeds were mixing breeds and housing both sheep and goat together (Ojango et al., 2014; Abraham et al., 2017).

There is no specific reproduction season for small ruminants in the UAE, since the county very close to the equator and length of day and night very close to each other all year round, where sires are all year round in the flocks. Uncontrolled mating leads to increase inbreeding depression in the flock because it allows for the sires to mate their own mothers, daughters and sisters (Ahmed et al., 2015; Asefa et al., 2015), though, it allows for lambing and kidding to be distributed during the whole year. On average only $5.03 \%$ and $33.20 \%$, respectively, of adult females and males are culled annually from a flock of small ruminants (Table 5). This low culling rate is due to that many farmers do not practice culling at all as they leave animals to die naturally in their flocks regardless of productivity. Though, female culling rate was significantly influenced by gender of farmers $(\mathrm{P}<0.05)$ and region $(\mathrm{P}<0.001)$. Female animals culling rate was higher by male farmers than that by female farmers and higher by Al-Ain farmers than that by the farmers of the other two regions. Male culling rate was significantly $(\mathrm{P}<0.05)$ influenced only by flock size as small flocks culling rate was more than doubled the other two sizes which could be just a numerical issue. Also, replacement rate is very low as adult females survive for 5.81 years in the flock with no significant effect of any studied factors while adult males survive for 5.40 years in the flock with only significantly $(\mathrm{P}<0.01)$ influenced by gender of farmers as adult males survive longer by the female farmers.

Almost $50 \%$ of the farmers mix young animals with all different ages together (Table 5). These farmers leave the young lambs and kids to suckle their dams together with other non-pregnant

Table 5 Factors influencing application of certain management practices by farmers of Abu-Dhabi Emirate in their farms

\begin{tabular}{|c|c|c|c|c|c|c|c|c|c|}
\hline Variable & $\begin{array}{c}\text { Quarantine } \\
\%\end{array}$ & $\begin{array}{c}\text { Fattening } \\
\%\end{array}$ & $\begin{array}{c}\text { Breed } \\
\text { purity } \\
\%\end{array}$ & $\begin{array}{c}\text { Mix } \\
\text { breeds } \\
\%\end{array}$ & $\begin{array}{c}\text { Female } \\
\text { culling } \\
\%\end{array}$ & $\begin{array}{c}\text { Male culling } \\
\%\end{array}$ & $\begin{array}{c}\text { Female life } \\
\text { Years }\end{array}$ & $\begin{array}{l}\text { Males life } \\
\text { years }\end{array}$ & $\begin{array}{c}\text { Mix ages } \\
\%\end{array}$ \\
\hline Overall & 59.3 & 71.3 & 71.3 & 29.1 & $5.03 \pm 0.45$ & $33.20 \pm 4.63$ & $5.81 \pm 0.12$ & $5.40 \pm 0.12$ & 49.1 \\
\hline Gender of farmers & 0.040 & 0.81 & 0.52 & 0.19 & 0.041 & 0.71 & 0.80 & 0.0083 & 0.56 \\
\hline Male & 62.1 & 71.5 & 72.0 & 27.5 & $2.79 \pm 0.75^{b}$ & $35.23 \pm 7.91$ & $6.00 \pm 0.21$ & $5.45 \pm 0.19^{b}$ & 48.3 \\
\hline Female & 47.5 & 70.0 & 67.8 & 36.2 & $5.10 \pm 1.18^{\mathrm{a}}$ & $30.78 \pm 12.54$ & $6.08 \pm 0.34$ & $6.27 \pm 0.32^{a}$ & 52.5 \\
\hline Region & $<0.0001$ & $<0.0001$ & 0.077 & 0.14 & $<0.0001$ & 0.088 & 0.17 & 0.059 & $<0.0001$ \\
\hline Abu-Dhabi & 34.7 & 49.4 & 66.7 & 28.8 & $2.77 \pm 1.05^{\mathrm{b}}$ & $51.64 \pm 11.15$ & $5.61 \pm 0.30$ & $5.42 \pm 0.27$ & 72.8 \\
\hline Al-Ain & 57.3 & 75.3 & 69.4 & 32.4 & $7.01 \pm 0.92^{\mathrm{a}}$ & $31.15 \pm 9.71$ & $6.13 \pm 0.26$ & $6.18 \pm 0.25$ & 44.8 \\
\hline Al-Dhafra & 96.6 & 88.5 & 83.1 & 19.0 & $2.06 \pm 1.33^{\mathrm{b}}$ & $16.23 \pm 14.08$ & $6.38 \pm 0.37$ & $5.98 \pm 0.35$ & 30.6 \\
\hline Properety type & 0.0047 & $<0.0001$ & 0.19 & 0.82 & 0.39 & 0.22 & 0.49 & 0.087 & 0.043 \\
\hline Registered farm & 38.6 & 40.4 & 72.3 & 25.5 & $2.73 \pm 1.39$ & $43.59 \pm 14.77$ & $6.06 \pm 0.38$ & $5.96 \pm 0.36$ & 61.7 \\
\hline Mixed farming & 59.6 & 82.3 & 75.0 & 30.2 & $4.68 \pm 0.90$ & $35.02 \pm 9.50$ & $5.84 \pm 0.26$ & $5.49 \pm 0.24$ & 43 \\
\hline Random farm & 67.7 & 67.3 & 64.8 & 28.9 & $4.42 \pm 1.01$ & $20.41 \pm 10.73$ & $6.21 \pm 0.29$ & $6.12 \pm 0.27$ & 53.3 \\
\hline Flock size $^{1}$ & 0.0024 & 0.27 & 0.90 & 0.55 & 0.41 & 0.047 & 0.29 & 0.56 & $<0.0001$ \\
\hline Small & 47.6 & 65.4 & 70.2 & 33.0 & $4.55 \pm 0.99$ & $50.35 \pm 10.47^{\mathrm{a}}$ & $5.99 \pm 0.28$ & $6.04 \pm 0.26$ & 65.4 \\
\hline Medium & 60.0 & 73.6 & 72.7 & 26.6 & $4.24 \pm 0.97$ & $24.85 \pm 10.29^{b}$ & $5.82 \pm 0.27$ & $5.74 \pm 0.26$ & 46.6 \\
\hline Large & 72.6 & 74.7 & 70.5 & 28.1 & $3.05 \pm 1.15$ & $23.83 \pm 12.18^{\mathrm{b}}$ & $6.30 \pm 0.32$ & $5.79 \pm 0.30$ & 34.1 \\
\hline Flock type & 0.70 & 0.15 & 0.0039 & 0.55 & 0.64 & 0.81 & 0.46 & 0.21 & 0.11 \\
\hline Pure goat & 52.9 & 63.6 & 58.8 & 35.3 & $3.93 \pm 1.51$ & $37.71 \pm 16.05$ & $6.37 \pm 0.43$ & $5.95 \pm 0.39$ & 58.8 \\
\hline Pure sheep & 61.8 & 81.0 & 87.9 & 24.6 & $3.40 \pm 1.20$ & $27.19 \pm 12.67$ & $5.91 \pm 0.34$ & $6.07 \pm 0.33$ & 37.9 \\
\hline Mixed flocks & 59.6 & 69.9 & 68.9 & 29.3 & $4.51 \pm 0.68$ & $34.12 \pm 7.21$ & $5.83 \pm 0.19$ & $5.55 \pm 0.18$ & 50.4 \\
\hline
\end{tabular}


animals until they dry naturally with no specific weaning age. However, leaving all ages together increases the mortality rate for the young animals (Asefa et al., 2017). Though, significant (P < 0.001) differences were found among different regions; farmers of Abu-Dhabi region were mixing different ages together the most followed by Al-Ain farmers. Also, different property types were significantly $(\mathrm{P}<0.05)$ different in mixing different ages together; more farmers of the registered animal farms were mixing different ages than other property types farmers and the least were farmers of the mixed farming. Though as expected, mixing animals of different ages was significantly $(\mathrm{P}<0.001)$ decreasing by increasing the flock size. This is because as flock size increase more pens would be required to house the animals, therefore, some will be available to house the young animals separated from the older ones.

Using modern reproduction techniques is very rare among farmers in Abu-Dhabi Emirate. From all interviewed farmers only two were using progesterone sponges and one using artificial insemination. Although, ten farmers demonstrated their preference for using artificial insemination in their small ruminants for genetic improvement, cross-breeding and reducing the cost of keeping sires.

\section{Conclusion}

This is the first study to describe the production system of small ruminants in Abu-Dhabi Emirate. The tradition of Emirati people is to keep small ruminants mainly for home consumption while only less than 5\% keep them as a business. The main purpose for keeping small ruminants in the Abu-Dhabi Emirate was meat production while milk production was of less concern for both sheep and goat. Farmers were mostly keeping mixed flocks of 16 and 18 different pure breeds of sheep and goats respectively, in addition to different crossbreds. Most farmers do not interfere with the daily care of their flocks. Some good practices are needed to be applied to their farms. The findings of this study create a baseline for understanding the production system of small ruminants in Abu-Dhabi Emirate as the first step in a sustainable production improvement and execution of effective extension program to farmers and labor to improve productivity.

\section{Conflict of interest}

The authors declare no conflict of interest regarding the information provided in the manuscript.

\section{Aknowlegements}

The authors are grateful to Abu-Dhabi Food Control Authority (ADFCA), Abu-Dhabi, UAE, for the financial support and to all persons who helped and gave support in achieving this study and it is hard to mention their names.

\section{References}

Abraham H, Gizaw S, Urge M (2017) Begait Goat Production Systems and Breeding Practices in Western Tigray, North Ethiopia. Open Journal of Animal Sciences 7: 198-212.

Abu-Dhabi Food Control Authority (ADFCA) (2013) Statistics Book. Abu-Dhabi Emirate, UAE.

Abu-Dhabi Food Control Authority (ADFCA) (2016) Statistics Book. Abu-Dhabi Emirate, UAE.

Abu-Zanat MMW, Miqdady HA, Tabbaa MJ (2005) Production systems of small ruminants in Middle Badia of Jordan. Dirasat 32:205-214.

Abu-Zanat MMW, Tabbaa MJ (2004) Effect of drought on feed resources and performance of small ruminants in the Northern Badia of Jordan. Dirasat 31:347-354.

Ahmed S, Kefelegne K, Kefena E (2015) Breeding objective, selection criteria and breeding practice of indigenous goats in western Ethiopia: Implications for sustainable genetic improvement. Greener Journal of Agricultural Sciences 5: 167176, http://doi.org/10.15580/GJAS.2015.5.072715105.

Al-Atiyat RM, Al_Tamimie H, Salameh N, Tabbaa MJ (2015) Genetic diversity of different Jordan goat breeds using microsatellite markers. The Journal of Animal \& Plant Sciences 25: 1532-1539.

Alhadrami GA, Nigm AA, Kholif AM, Abdalla OM (1997) Effect of roughage to concentrate ratio on performance and carcass characteristics of local lambs in the UAE. Arab Gulf Journal of Scientific Research 15: 137-148.

Al-Khaza'leh J, Reiber C, Ogutu JO, Valle Zárate A (2016) Goat Breeds Performance under Different Farming Systems and Conditions of Water Availability in the Karak Governorate, Jordan. Jordan Journal of Agricultural Sciences 12: 441-458.

Al-Shorepy SA (2004) Genetic parameters for indigenous sheep in the United Arab Emirates. 15th conference for Association for the Advancement of Animal Breeding and Genetics Proceeding for the Fifteenth Conference 343-346.

Al-Shorepy SA, Alhadrami GA, Abdulwahab K (2002) Genetic and phenotypic parameters for early growth traits in Emirati goat. Small Ruminant Research 45: 217-223. 
Asefa B, Abate T, Adugna E (2017) Assessment of Indigenous Sheep Production Systems in Bale Zone, Oromia Regional State, Ethiopia. American Journal of Agricultural Science 4: 126-137.

Asefa B, Kebede K, Effa K (2015) Breeding objective, selection criteria and breeding system of indigenous goats types in Bale Zone, Oromia Ethiopia. Journal of Agricultural Research Innovation \& Technology 5: 7-15.

Dagnew Y, Urge M, Tadesse Y, Gizaw S (2017) Sheep Production and Breeding Systems in North Western Lowlands of Amhara Region, Ethiopia: Implication for Conservation and Improvement of Gumz Sheep Breed. Open Journal of Animal Sciences 7: 179-197

Degen A (2007) Sheep and goat milk in pastoral society. Small Ruminant Research 68: 7-19.

Duguma G, Mirkena T, Haile A, Iñiguez L, Okeyo AM, Tibbo M, Rischkowsky B, Sölkner J, Wurzinger M (2010) Participatory approaches to investigate breeding objectives of livestock keepers. Livestock Research for Rural Development 22: Article 64.

FAO (2012) Animal Production and Health Guidelines No. 11. Rome.

Federal Competitiveness and Statistics Authority (FCSA) (2016) Statistical Report. Abu-Dhabi Emirate, UAE.

Galal S (2005) Biodiversity in goats. Small Ruminant Research 60: $75-81$.

Gatew H, Hassen H, Kebede K, Haile A, Lobo RNB, Yetayew A, Rischkowsky B (2017) Husbandry practices and phenotypic characteristics of indigenous goat populations in Ethiopia. African Journal of Agricultural Research 12: 2729-2741

Kebede T, Haile A, Dadi H (2012) Smallholder goat breeding and flock management practices in the central rift valley of Ethiopia. Tropical Animal Health and Production 44:999-1006.

Lopes FB, Silvaa MC, Miyagi ES, Fioravanti MCS, Facó O, Lôbo R, McManus C (2013) Comparison of selection indexes for dairy goats in the tropics. Acta Scientiarum Animal Sciences Maringá 35: 321-328.

Mbuku SM, Kosgey IS, Kahi AK (2006) Indigenous breeding practices of pastoralist goat keepers in northern Kenya. 8th World Congress on Genetics Applied to Livestock Production, 13-18 August 2006, Belo Horizonte, MG, Brasil.

Nandolo W, Wurzinger M, Meszaros G, Van Tassell C, Gondwe
T, Mulindwa H, Lamuno D, Solkner J (2016) Identification of breeding objectives in community-based goat breeding programmes in Malawi. 24th International Symposium on "Animal Science Days", Ptuj, Slovenia, September 21st-23rd, 2016. Acta argiculturae Slovenica, Supplement 5: 103-108.

Notter DR (2012) Genetic Improvement of reproductive efficiency of sheep and goat. Animal Reproduction Science 130:147-151

Ojango JMK, Oyieng EP, Audho J, Okeyo AM (2014) Indigenous sheep to help improve market access and livelihood security among pastoralists in Kenya: Results of a baseline survey. International Livestock Research Institute, Nairobi, Kenya

Onzima RB, Gizaw S, Kugonza DR, van Arendonk JAM, Kanis E (2018) Production system and participatory identification of breeding objective traits for indigenous goat breeds of Uganda. Small Ruminant Research 163: 51-59. https://doi.org/10.1016/j.smallrumres.2017.07.007.

Rose IJ (2014) Breeding strategies to make sheep farms resilient to uncertainty. $\mathrm{PhD}$ thesis submitted to the Wageningen University, Wageningen, NL.

Santos BFS, McHugh N, Byrne TJ, Berry DP, Amer PR (2015) Comparison of breeding objectives across countries with application to sheep indexes in New Zealand and Ireland. Journal of Animal Breeding \& Genetics 132: 144-154.

SAS Institute (2009) SAS User Guide. Cary, NC, USA.

Sherif S, Al-Shorepy S, Al-Juboori A, Fathelrahman E (2014) Sustainability of Sheep and Goat Production Systems under United Arab Emirates' Arid land Constraints. APCBEE Procedia 8: $236-241$.

Tabbaa MJ, Al-Atiyat R (2009) Breeding objectives, selection criteria and factors influencing them for goat breeds in Jordan. Small Ruminant Research 8: 8-15

Tabbaa MJ, Hassanin HH (2017) Production systems of village chickens in the Abu-Dhabi Emirate, UAE. African Journal of Agricultural Research 12: 2986-2994.

Tibério ML, Diniz F (2014) Sheep and Goat Production in Portugal: A Dynamic View. Modern Economy 5: 703-722. http://dx.doi.org/10.4236/me.2014.56066

Veterinary Services Centre for Epidemiology and Animal Health (VSCEAH) (2015) Health Management and Biosecurity Practices on U.S. Sheep Operations. USDA, APHIS, VS Info Sheet. 